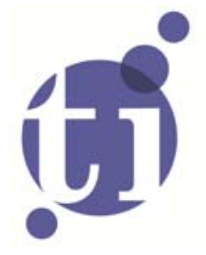

\title{
Preference Elicitation in Generalized Data Envelopment Analysis: \\ In Search of a New Energy Balance in Japan
}

Soushi Suzukir

Peter Nijkamp 2

Piet Rietveld ${ }^{2}$

\footnotetext{
1 Hokkai-Gakuen University, Japan;

2 Faculty of Economics and Business Administration, VU University Amsterdam, and Tinbergen Institute, The Netherlands.
} 
Tinbergen Institute is the graduate school and research institute in economics of Erasmus University Rotterdam, the University of Amsterdam and VU University Amsterdam.

More TI discussion papers can be downloaded at http://www.tinbergen.nl

Tinbergen Institute has two locations:

Tinbergen Institute Amsterdam

Gustav Mahlerplein 117

1082 MS Amsterdam

The Netherlands

Tel.: +31(0)205251600

Tinbergen Institute Rotterdam

Burg. Oudlaan 50

3062 PA Rotterdam

The Netherlands

Tel.: +31(0)10 4088900

Fax: $+31(0) 104089031$

Duisenberg school of finance is a collaboration of the Dutch financial sector and universities, with the ambition to support innovative research and offer top quality academic education in core areas of finance.

DSF research papers can be downloaded at: http://www.dsf.nl/

Duisenberg school of finance

Gustav Mahlerplein 117

1082 MS Amsterdam

The Netherlands

Tel.: +31(0)20 5258579 


\title{
Preference Elicitation in Generalized Data Envelopment Analysis
}

\section{In Search of a New Energy Balance in Japan}

\author{
Soushi Suzuki ${ }^{\mathrm{a}}$ \\ Peter Nijkamp ${ }^{b}$ \\ Piet Rietveld \\ ${ }^{a}$ Hokkai-Gakuen University, Department of Life Science and Technology, Japan \\ ${ }^{b}$ VU University Amsterdam, Department of Spatial Economics, and Tinbergen Institute, The Netherlands
}

\begin{abstract}
The recent dramatic change in energy supply in Japan has prompted a search for a new energy-environment-economic efficiency policy, in which a compromise has to be found between a sufficient supply of energy resources, the development of low carbon emission technology, and a continuation of economic growth. The prefectures in Japan - 46 in total (excluding Tokyo) - are regarded as the institutional agents or decision-making units (DMUs) which are responsible for the design of a new sustainable energy balance in these regions. The main challenge is now to design an efficient energy-environment-economic system.

The present paper aims to develop a balanced decision-support tool for achieving an efficient energy supply in all Japanese prefectures. To that end, a new variant of Data Envelopment Analysis (DEA) is presented, which is characterized by two integrated features: (i) the use of a general Euclidean Distance Method (EDM) to achieve the most appropriate movement towards the efficiency frontier surface (in contrast to the standard radial movement, leading to a uniform proportional input reduction - or uniform proportional output increase); (ii) the incorporation of preference-based (PB) adjustments in efficiency strategies regarding the input reduction allocation - or the output increase allocation - of DMUs in order to balance rigorous efficiency decisions with political priorities at the regional level. This paper illustrates this new methodology by means of an application to prefectural energy efficiency strategies in Japan.
\end{abstract}

Keywords: Data Envelopment Analysis (DEA); Euclidean Distance Minimization (EDM); Preference Based (PB); Energy-Environment-Economic efficiency

JEL code: C C0, R58, Q48 


\section{Introduction}

Japan is faced with the "Fukushima' problem, meaning a nuclear accident leading to electrical power shortage. This problem relates to a non-balanced "Energy-Environment-Economic" policy which does not, but should, incorporate "electrical power saving", "low carbon emission", and "economic growth". Although it is difficult at this stage, it is necessary to make an effort to achieve a more balanced and more efficient "Energy-Environment-Economic" policy in Japan.

A popular tool to judge efficiency is Data Envelopment Analysis (DEA). Seiford (2005) mentions that more than 2500 articles appeared on DEA. Thus comparative efficiency analysis has become well established field. DEA was developed to analyze the relative efficiency of a decision-making unit (DMU), by constructing a piecewise linear production frontier, and projecting the performance of each DMU onto the frontier. A DMU that is located on the frontier is efficient, whereas a DMU that is not on the frontier is inefficient. An inefficient DMU can become efficient by reducing its inputs, or by increasing its outputs. In the standard DEA approach, this is achieved by a uniform reduction in all inputs (or a uniform increase in all outputs). But, there are an infinite number of improvements to reach the efficient frontier, and hence there are many solutions if a DMU plans to enhance its efficiency.

The existence of many possible efficiency improvement solutions has prompted a rich literature on the methodological integration of the MOLP (Multiple Objective Linear Programming) and the DEA models. The first contribution was made by Golany (1988) who proposed an interactive MOLP procedure, which aimed at generating a set of efficient points for a DMU. This model allows a decision maker to select the preferred set of output levels, given the input levels. Next, Thanassoulis and Dyson (1992) developed adjusted models which can be used to estimate alternative input and output levels, in order to render relatively inefficient decision making units more efficient. These models are able to incorporate preferences for a potential improvement of individual input and output levels. The resulting target levels reflect the user's relative preference over alternative paths to efficiency. Joro et al. (1998) demonstrated the analytical similarity of a DEA model and a Reference Point Model in a MOLP formulation from a mathematical viewpoint. In addition, the Reference Point Model provides suggestions which make it possible to search freely on the efficient frontier for good solutions or for the most-preferred solution based on the decision maker's preference structure. In addition, Halme et al. (1999) developed a Value Efficiency Analysis (VEA), which included the decision maker's preference information in a DEA model. The foundation of VEA originates from the Reference Point Model in a MOLP context. Here the decision maker identifies the most preferred solution, so that each DMU can be evaluated by means of the assumed value function based on the most preferred solution approach. 
A further development of this approach was made by Korhonen and Siljamäki (2002) who dealt with several practical aspects related to the use of a VEA. In addition, Korhonen et al. (2003) developed a multiple objective approach which allows for changes in the time frame. Further, Lins et al. (2004) proposed two multi-objective approaches that determine the basis for the incorporation of a posteriori preference information. The first of these models is called MORO (Multiple Objective Ratio Optimization), which optimizes the ratios between the observed and the target inputs (or outputs) of a DMU. The second model is MOTO (Multiple Objective Target Optimization), which directly optimizes the target values. In addition, Washio et al. (2012) suggested four types of improvements for making inefficient DMUs efficient in the CCR by introducing a decision maker's policy model with the minimal change of input and output values. And, finally, Yang et al. (2013) utilize DEA and Nash bargaining game theory to improve inefficient DMUs, in order to make an inefficient DMU Pareto Optimal for multiple perspectives, which can avoid being discontent with some particular perspectives; and change its attributes and provide various improvement schemes for decision makers.

Suzuki et al. (2010) proposed a Euclidean Distance Minimization (EDM) model that is based on a generalized distance function, and serves to improve the performance of a DMU by identifying the most appropriate movement towards the efficiency frontier surface. This approach may address both an input reduction and an output increase as a strategy for a DMU. A possible advantage of this model is that there is no need to incorporate the value judgment of a decision maker. Nevertheless it may also be attractive to develop it further to incorporate policy maker value judgments on political priorities.

In our study, we present a newly developed preference-based (PB) - EDM approach, which is suitable to incorporate a decision maker's value judgment for the allocation of an input reduction and an output augmentation in an efficiency improvement projection.

The above-mentioned PB model is illustrated on the basis of an application to an efficiency analysis of energy use in the Japanese prefectures.

\section{Efficiency Improvement Projection in DEA}

The standard Charnes et al. (1978) model (hereafter abbreviated as the CCR-input model) for a given $\operatorname{DMU}_{j}(j=1, \cdots, J)$ to be evaluated in any trial $o$ (where $o$ ranges over $\left.1,2 \ldots, J\right)$ can be represented as the following fractional programming $\left(F P_{o}\right)$ problem: 


$$
\begin{array}{ll}
\left(F P_{o}\right) \quad \max _{v, u} \quad \theta=\frac{\sum_{s} u_{s} y_{s o}}{\sum_{m} v_{m} x_{m o}} \\
\text { s.t. } \quad \frac{\sum_{s} u_{s} y_{s j}}{\sum_{m} v_{m} x_{m j}} \leq 1 \quad(j=1, \cdots, J) \\
v_{m} \geq 0, u_{s} \geq 0,
\end{array}
$$

where $\theta$ represents an objective variable function (efficiency score); $x_{m j}$ is the volume of input $m$ $(m=1, \ldots, M)$ for $\mathrm{DMU}_{\mathrm{j}}(j=1, \ldots, j) ; y_{s j}$ is the output $s(s=1, \ldots, s)$ of $\mathrm{DMU}_{\mathrm{j}}$; and $v_{m}$ and $u_{s}$ are the weights given to input $m$ and output $s$, respectively. Model (2.1) is usually called an input-oriented CCR model, while its reciprocal (i.e. an interchange of the numerator and denominator in the objective function (2.1), with a specification as a minimization problem under an appropriate adjustment of the constraints) is known as an output-oriented CCR model. Model (2.1) is obviously a fractional programming model, which may be solved stepwise by first assigning an arbitrary value to the denominator in (2.1), and then maximizing the numerator.

The improvement projection $\left(\hat{x}_{o}, \hat{y}_{o}\right)$ can now be defined in (2.2) and (2.3) as:

$$
\begin{aligned}
& \hat{x}_{o}=\theta^{*} x_{o}-s^{-*} ; \\
& \hat{y}_{o}=y_{o}+s^{+*} .
\end{aligned}
$$

These equations indicate that efficiency of $\left(x_{0}, y_{0}\right)$ for $\mathrm{DMU}_{\mathrm{o}}$ can be improved if the input values are reduced radially by the ratio $\theta^{*}$, and the input excesses $s^{-*}$ are eliminated (see Figure 1).

The original DEA models presented in the literature have focused on a uniform input reduction or a uniform output increase in the efficiency-improvement projections, as shown in Figure 1 ( $\theta^{*}$ $\left.=\mathrm{OC}^{\prime} / \mathrm{OC}\right)$.

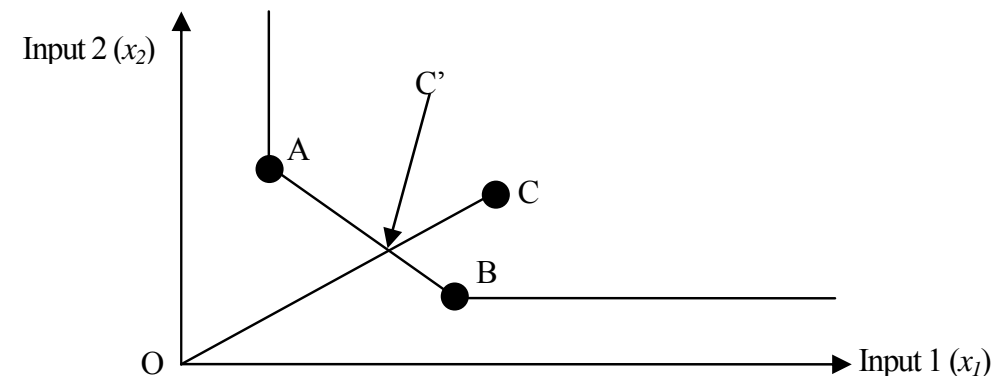

Figure 1 Illustration of original DEA projection in input space 


\section{The Euclidean Distance Minimization (EDM) Approach}

As mentioned, the efficiency improvement solution in the original CCR-input model requires that the input values are reduced radially by a uniform ratio $\theta^{*}\left(\theta^{*}=\mathrm{OC}^{\prime} / \mathrm{OC}\right.$ in Figure 1$)$.

The $\left(v^{*}, u^{*}\right)$ values obtained as an optimal solution for formula (2.1) result in a set of optimal weights for $\mathrm{DMU}_{\mathrm{o}}$. Hence, $\left(v^{*}, u^{*}\right)$ is the set of most favourable weights for $\mathrm{DMU}_{\mathrm{o}}$, in the sense of maximizing the ratio scale. $v_{m}{ }^{*}$ is the optimal weight for the input item $m$, and its magnitude expresses how much in relative terms the item is contributing to efficiency. Similarly, $u_{s}{ }^{*}$ does the same for the output item $s$. These values show not only which items contribute to the performance of $\mathrm{DMU}_{\mathrm{o}}$ but also to what extent they do so. In other words, it is possible to express the distances (or alternatively, the potential increases) in improvement projections.

In this study, we use the optimal weights $u_{s}{ }^{*}$ and $v_{m}{ }^{*}$ from (2.1), and then describe the efficiency improvement projection model. A visual presentation of this approach (EDM projection) is given in Figures 5 and 6. In this approach a generalized distance function is employed to assist a DMU to improve its efficiency by a movement towards the efficiency frontier surface. The direction of efficiency improvement depends, of course, on the input/output data characteristics of the DMU. It is now appropriate to define projection functions for the minimization of distance by using a Euclidean distance in weighted spaces. As mentioned, a suitable form of multidimensional projection functions that serves to improve efficiency is given by a MOQP (Multiple Objective Quadratic Programming) model which aims to minimize the aggregated input reductions, as well as the aggregated output increasess. Thus, the EDM approach can generate a new contribution to efficiency enhancement problems in decision analysis by employing a weighted Euclidean projection function, and, at the same time, it may address both input reduction and output increase. We briefly describe the various steps.

First, the distance function $\mathrm{Fr}^{x}$ and $\mathrm{Fr}^{y}$ is specified by means of (3.1) and (3.2), which are defined by the Euclidean distance shown in Figures 2 and 3. Next, the following MOQP is solved by using $d_{m o}^{x}$ (a reduction of distance for $x_{i o}$ ) and $d_{s o}^{y}\left(\right.$ an increase of distance for $\left.y_{s o}\right)$ as variables:

$$
\begin{aligned}
& \min \mathrm{Fr}^{x}=\sqrt{\sum_{m}\left(v_{m}^{*} x_{m o}-v_{m}^{*} d_{m o}^{x}\right)^{2}} \\
& \min F r^{y}=\sqrt{\sum_{s}\left(u_{s}^{*} y_{s o}-u_{s}^{*} d_{s o}^{y}\right)^{2}}
\end{aligned}
$$


s.t. $\quad \sum_{m} v_{m}^{*}\left(x_{m o}-d_{m o}^{x}\right)=\frac{2 \theta^{*}}{1+\theta^{*}}$

$$
\begin{aligned}
& \sum_{s} u_{s}^{*}\left(y_{s o}+d_{s o}^{y}\right)=\frac{2 \theta^{*}}{1+\theta^{*}} \\
& x_{m o}-d_{m o}^{x} \geq 0 \\
& d_{m o}^{x} \geq 0 \\
& d_{s o}^{y} \geq 0,
\end{aligned}
$$

where $x_{m o}$ is the amount of input item $m$ for any arbitrary inefficient $\mathrm{DMU}_{\mathrm{o}}$, and $y_{\mathrm{so}}$ is the amount of output item $s$ for any arbitrary inefficient $\mathrm{DMU}_{0}$. The constraint functions (3.3) and (3.4) refer to the target values of input reduction and output augmentation. The fairness in the distribution of contributions from the input and output side to achieve efficiency is established as follows. The total efficiency gap to be covered by inputs and outputs is $\left(1-\theta^{*}\right)$. The input and the output side contribute according to their initial levels 1 and $\theta^{*}$, implying shares $\theta^{*} /\left(1+\theta^{*}\right)$ and $1 /\left(1+\theta^{*}\right)$ in the improvement contribution. Clearly, the contributions from both sides equal $\left(1-\theta^{*}\right)\left[\theta^{*} /\left(1+\theta^{*}\right)\right]$, and $\left(1-\theta^{*}\right)\left[1 /\left(1+\theta^{*}\right)\right]$. Hence, we find for the input reduction target and the output augmentation targets:

$$
\begin{aligned}
& \text { Input reduction target: } \sum_{m} v_{m}^{*}\left(x_{m o}-d_{m o}^{x}\right)=1-\left(1-\theta^{*}\right) \times \frac{1}{\left(1+\theta^{*}\right)}=\frac{2 \theta^{*}}{1+\theta^{*}} . \\
& \text { Output augmentation target: } \sum_{s} u_{s}^{*}\left(y_{s o}+d_{s o}^{y}\right)=\theta^{*}+\left(1-\theta^{*}\right) \times \frac{\theta^{*}}{\left(1+\theta^{*}\right)}=\frac{2 \theta^{*}}{1+\theta^{*}} \text {. }
\end{aligned}
$$

An illustration is given in Figure 2.

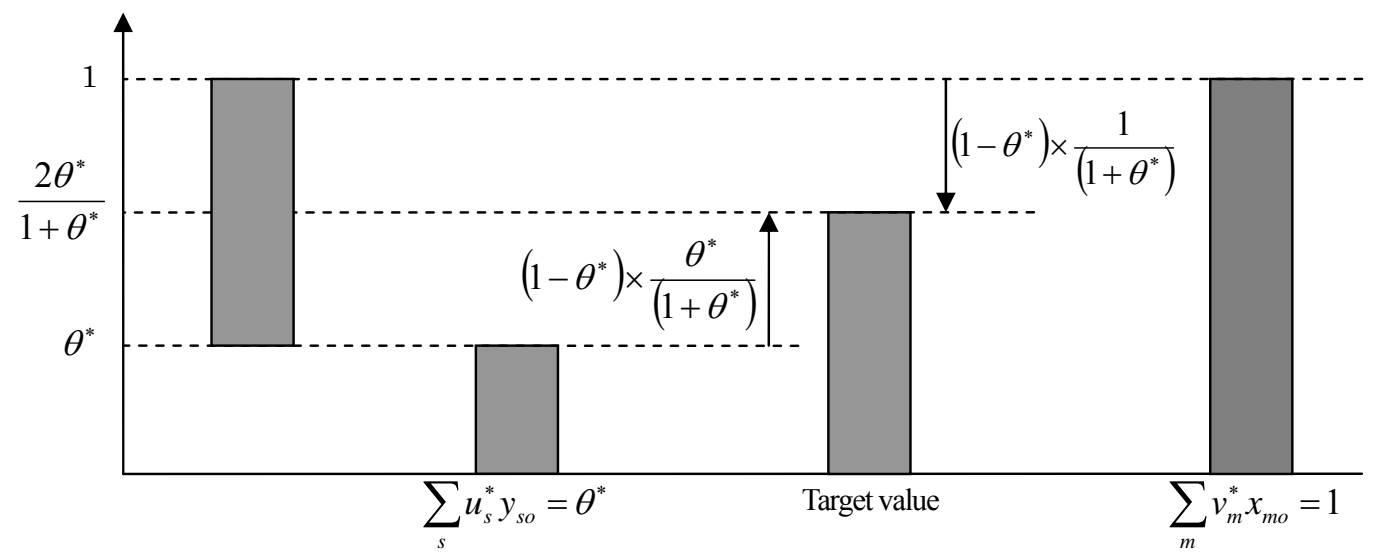


Figure 2 EDM model with an illustration of a balanced contribution of inputs and outputs to closing the efficiency gap

It is now possible to determine each optimal distance $d_{m o}^{x^{*}}$ and $d_{s o}^{y *}$ by using the MOQP model (3.1)-(3.7). The distance minimization solution for an inefficient $\mathrm{DMU}_{\mathrm{o}}$ can be expressed by means of formulas (3.10) and (3.11):

$$
\begin{aligned}
& x_{m o}^{*}=x_{m o}-d_{m o}^{x^{*}} ; \\
& y_{s o}^{*}=y_{s o}+d_{s o}^{y *} .
\end{aligned}
$$

By means of the EDM model, it is possible to present a new efficiency-improvement solution based on the standard CCR projection. This means an increase in new options for efficiency-improvement solutions in DEA. The main advantage of the EDM model is that it yields an outcome on the efficient frontier that is as close as possible to the DMU's input and output profile (see Figure 3).

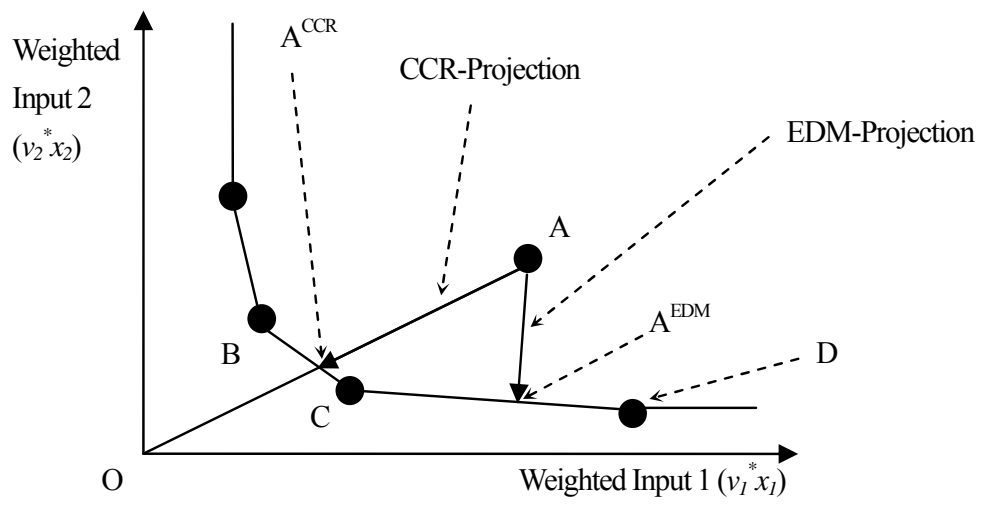

Figure 3 Degree of improvement of the EDM and the CCR projection in weighted input space

\section{Preference -based EDM approach}

In this study we propose a preference-based (hereafter PB) approach to the EDM model. The PB approach specifies an Output Augmentation Parameter (OAP) of the total efficiency gap $\left(1-\theta^{*}\right)$ in the EDM model. The value of the OAP ranges from 0 to 1. For example, if the OAP is specified to be 1.0, then the PB model can compute an efficiency-improving projection so that the total efficiency gap (1$\left.\theta^{*}\right)$ is fully allocated for output augmentation. If the OAP is specified to be 0.7 , then the PB model can compute an efficiency-improving projection so that 70 percent of the total efficiency gap $\left(1-\theta^{*}\right)$ is 
allocated for output augmentation, and 30 percent of the total efficiency gap (1- $\left.\theta^{*}\right)$ is allocated for input reduction. And, if the OAP is specified to be 0.0, then the PB model can compute an efficiency-improving projection so that the total efficiency gap $\left(1-\theta^{*}\right)$ is fully closed by input reduction.

This model uses the constraint functions (4.1) and (4.2), instead of the constraint functions (3.3) and (3.4) in the EDM model.

$$
\begin{array}{ll}
\text { s.t. } \quad & \sum_{m} v_{m}^{*}\left(x_{m o}-d_{m o}^{x}\right)=\theta^{*}+\operatorname{OAP}\left(1-\theta^{*}\right) ; \\
& \sum_{s} u_{s}^{*}\left(y_{s o}+d_{s o}^{y}\right)=\theta^{*}+O A P\left(1-\theta^{*}\right) .
\end{array}
$$

A visual presentation of constraint functions (4.1) and (4.2) is given in Figure 4.

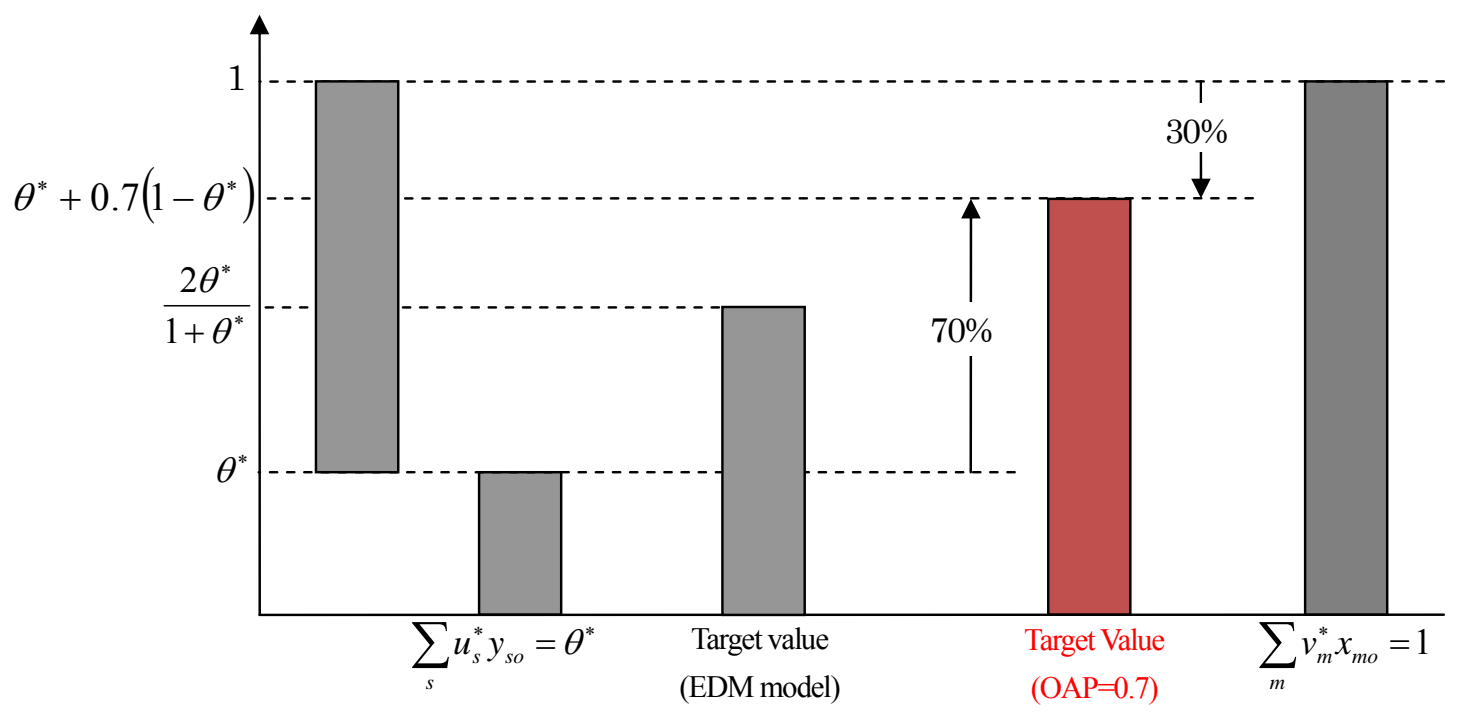

Figure 4 Illustration of the-PB EDM model with a value 0.7 for the OAP parameter 


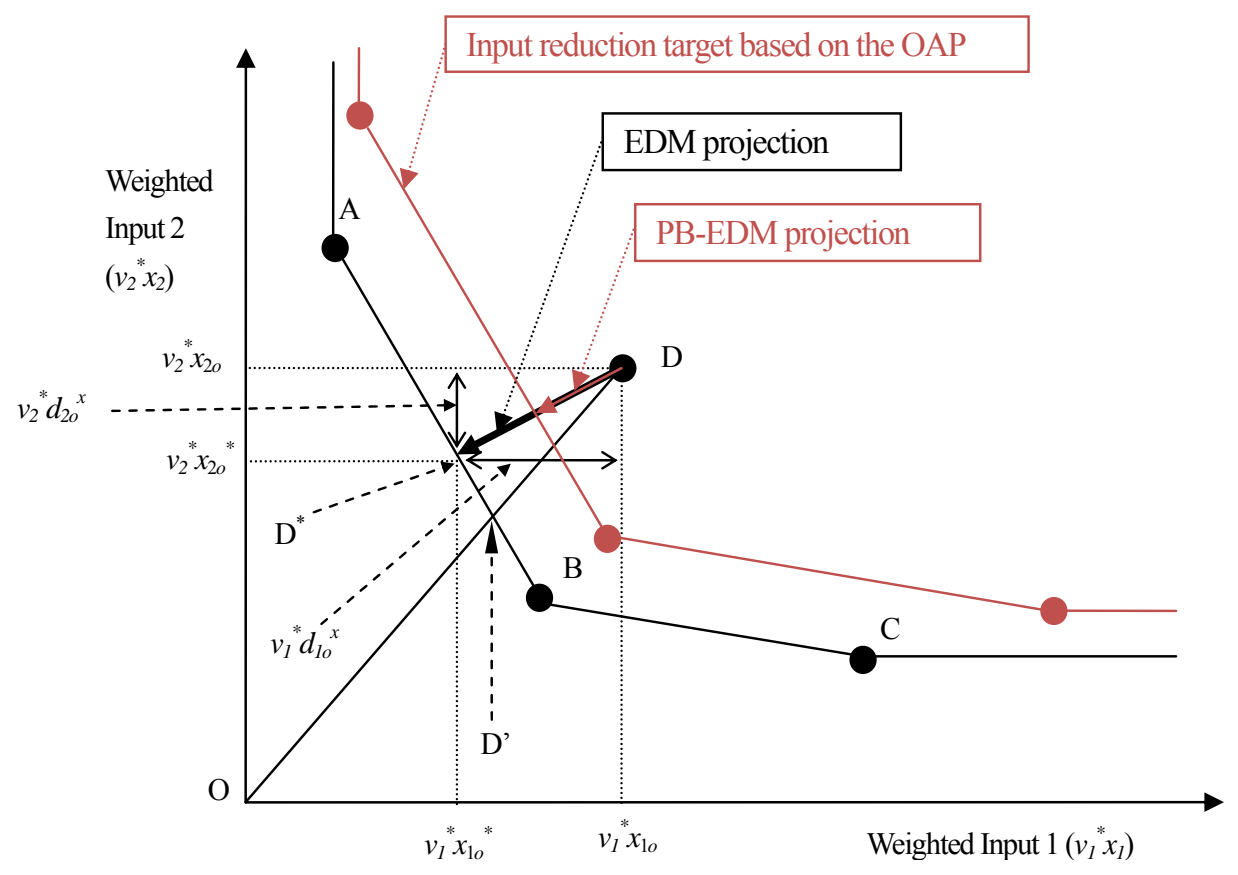

Figure 5 Illustration of the EDM and PB-EDM approach (Input- $v_{i}^{*} x_{i}$ space)

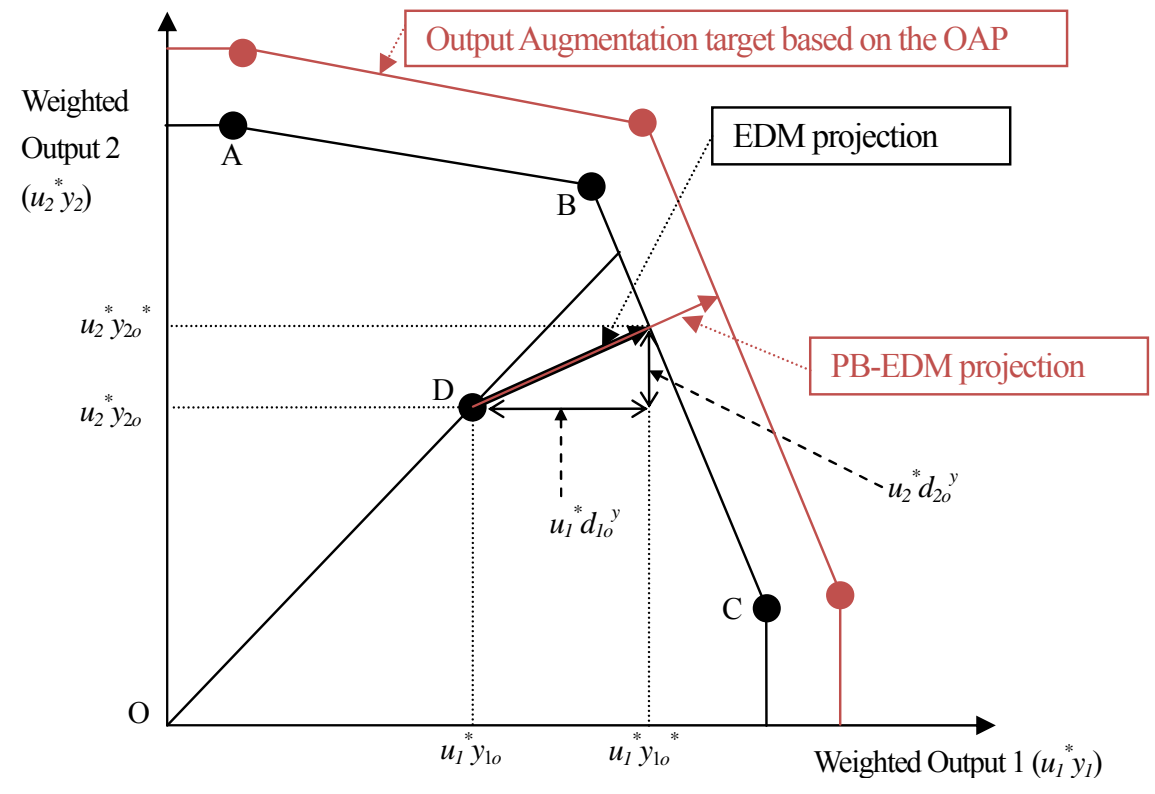

Figure 6 Illustration of the EDM approach (Output - $u_{r}^{*} \mathbf{y}_{r}$ space)

First, the PB model has arbitrarily specified the OAP (it is just a decision maker's value judgment for the allocation percentage of an output augmentation) of the total efficiency gap $\left(1-\theta^{*}\right)$. Next, the target values, which are allocated between input efforts and output efforts based on the OAP, are computed in 
Figure 4 using constraint functions (4.1) and (4.2). Finally, we can compute an input reduction value and an output increase value based on the EDM model. A visual presentation of this new PB-EDM projection is given in Figures 5 and 6. We call the model a Preference-based EDM model (PB-EDM).

\section{An application of PB-EDM Model for Energy-Environment-Economic efficiency in Japan.}

\subsection{Database and analysis framework}

In our empirical work, we use the following input and output data for a set of 46 prefectures in Japan, as shown in figure 7. We eliminated Tokyo in the DMUs in order to compute a realistic improving projection for each prefecture, because many headquarters of companies are based in Tokyo, which makes its GDP excessively large. Figure 7 presents the inputs and outputs considered in this analysis of regional efficiency.

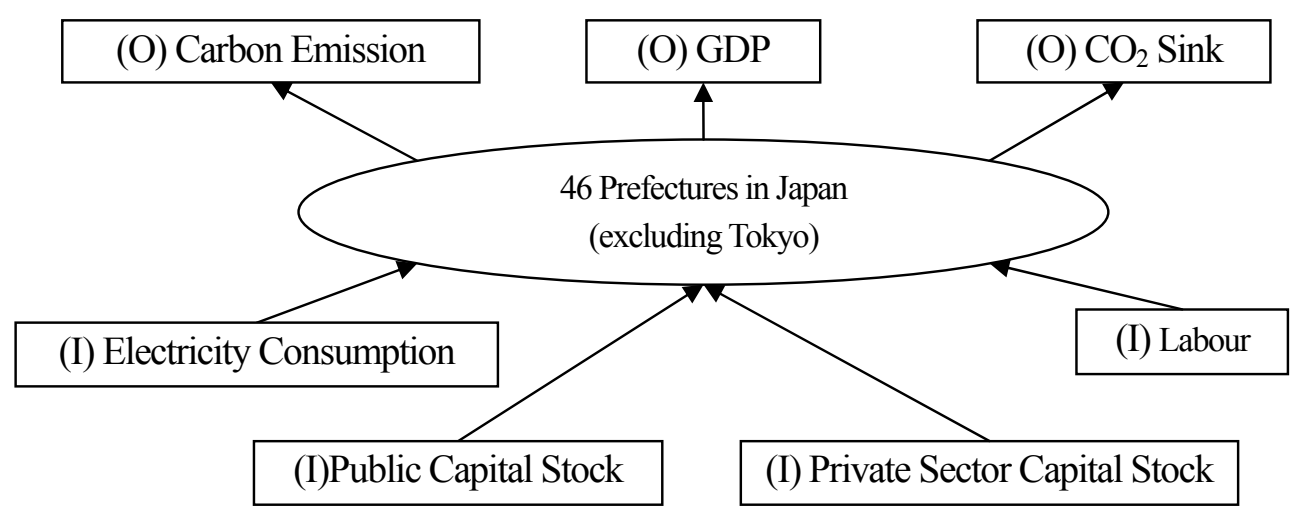

Figure 7 Inputs and Outputs of Energy-Environment-Economic efficiency

We consider four Inputs (I):

(I) Electricity Consumption in each prefecture (Giga Watt hours / year) (2008);

(I) Public capital stock in each prefecture (million yen) (2008);

(I) Private-sector capital stock in each prefecture (million yen) (2008);

(I) Labour in each prefecture (employed persons) (2005).

Further, three Outputs $(\mathrm{O})$ are incorporated:

(O) GDP in each prefecture (million yen / year) (2008);

(O) Carbon emission in each prefecture (inverse number) (Kilo Tons / year) (2008); 
(O) $\mathrm{CO}_{2}$ sink in each prefecture (Tons / year) (2000).

An explanation for the inputs and outputs are as follows:

\section{(I) Electricity Consumption (hereafter EC) in each prefecture (Giga Watt hours / year) (2008)}

This data set was obtained from statistical reports on energy consumption, and the inter-industry relations table. It was estimated from the energy consumption basic unit for each industry and sector. The sectors included sectors are: the industrial sector, the consumer and service sector, the consumer and residential sector, and the household car sector. We excluded the primary energy supply sector, the energy conversion sector, and the traffic and cargo sector, because they supply services beyond the prefecture boundaries.

This data set also accounts for consequential (implicit) energy consumption when one prefecture is supplied from other prefectures, in order to appreciate "pseudo-energy saving".

[Data source: "statistical report on energy consumption for each prefecture", and "statistics report on comprehensive strategy for energy consumption and environment (2008)", Agency for Natural Resources and Energy, Ministry of the Economy, Trade and Industry in Japan] (see Figure A1-A4 in the Appendix)

\section{(I) Public Capital Stock (hereafter PCS) in each prefecture (million yen) (2008)}

This data set presents the public capital stock in sectors such as transport, national conservation, health care, and educational. [Data source: Economic and Fiscal model for Prefectures, Cabinet Office, Government of Japan, http://www5.cao.go.jp/keizai3/pref_model.html]

\section{(I) Private Sector capital stock in prefecture (million yen) (2008) (PSCS hereafter)}

This dataset presents the private sector capital stock in sectors such as agriculture, forestry and fisheries, mining, construction, manufacturing, wholesale and retail trade, finance and insurance, real estate, transportation and communication, utilities, services. [Data source: Economic and Fiscal model for Prefectures, Cabinet Office, Government of Japan, http:/www5.cao.go.jp/keizai3/pref_model.html]

\section{(I) Labour in each prefecture (employed persons) (2005)}

This data set is based on "Census Return 2005". [Data source: Statistics Bureau, Ministry of Internal Affairs and Communication, http://www.e-stat.go.jp/SG1/estat/List.do?bid=000001036794\&cycode=0]

(O) GDP in each prefecture (million yen / year) (2008) 
This data set is based on the "National Accounts of Japan". [Data source: Economic and Fiscal model for the Prefectures, Cabinet Office, Government of Japan, http://www5.cao.go.jp/keizai3/pref_model.html]

(O) Carbon Emission (hereafter CE) in each prefecture (inverse number) (Mega Tons / year) (2008)

This data set is based on statistical reports on energy consumption, and the inter-industry relations table. It was estimated from the carbon emission basic unit for each industry and sector. The sectors included are the same as those used in electricity consumption above.

The data set even accounts for consequential (implicit) carbon emission, when one prefecture is supplied from the other prefectures, in order to appreciate "pseudo-emissions reduction".

[Data source: "statistical report on energy consumption for each prefecture", and "statistics report on comprehensive strategy for energy consumption and environment (2008)", Agency for Natural Resources and Energy, Ministry of the Economy, Trade and Industry]

\section{(O) $\mathrm{CO}_{2} \operatorname{Sink}$ (hereafter Sink) in each prefecture (Tons / year) (2000)}

This data set is based on "Land-Use, Land Use Change, and Forestry (IPCC 2000)", and the carbon sink basic unit for needle leaf tree (artificial forest), broad-leaf tree (artificial forest), needle leaf tree (natural forest), and broad-leaf tree (natural forest).

[Data source: Sugihara, H. et al. "carbon pool of Japanese islands", Studies in Regional Policy (Development Bank of Japan), Vol.11, pp.1-49, 2004].

In our application, we first applied the CCR-I model, after which its results were used to determine the CCR-I and EDM projections. Additionally, we applied the PB-EDM model. Finally, these results were compared with each other.

\subsection{Efficiency evaluation based on the CCR-I model}

The efficiency evaluation results for each of the 46 prefectures based on the CCR-I model are given in Figure 8. The figure shows that 19 prefectures are efficient DMUs. The remaining 27 prefectures are inefficient. In particular Yamaguchi (0.875), Niigata (0.846), Wakayama (0.832), Ibaraki (0.808), and Ehime (0.787) have low efficiency. 


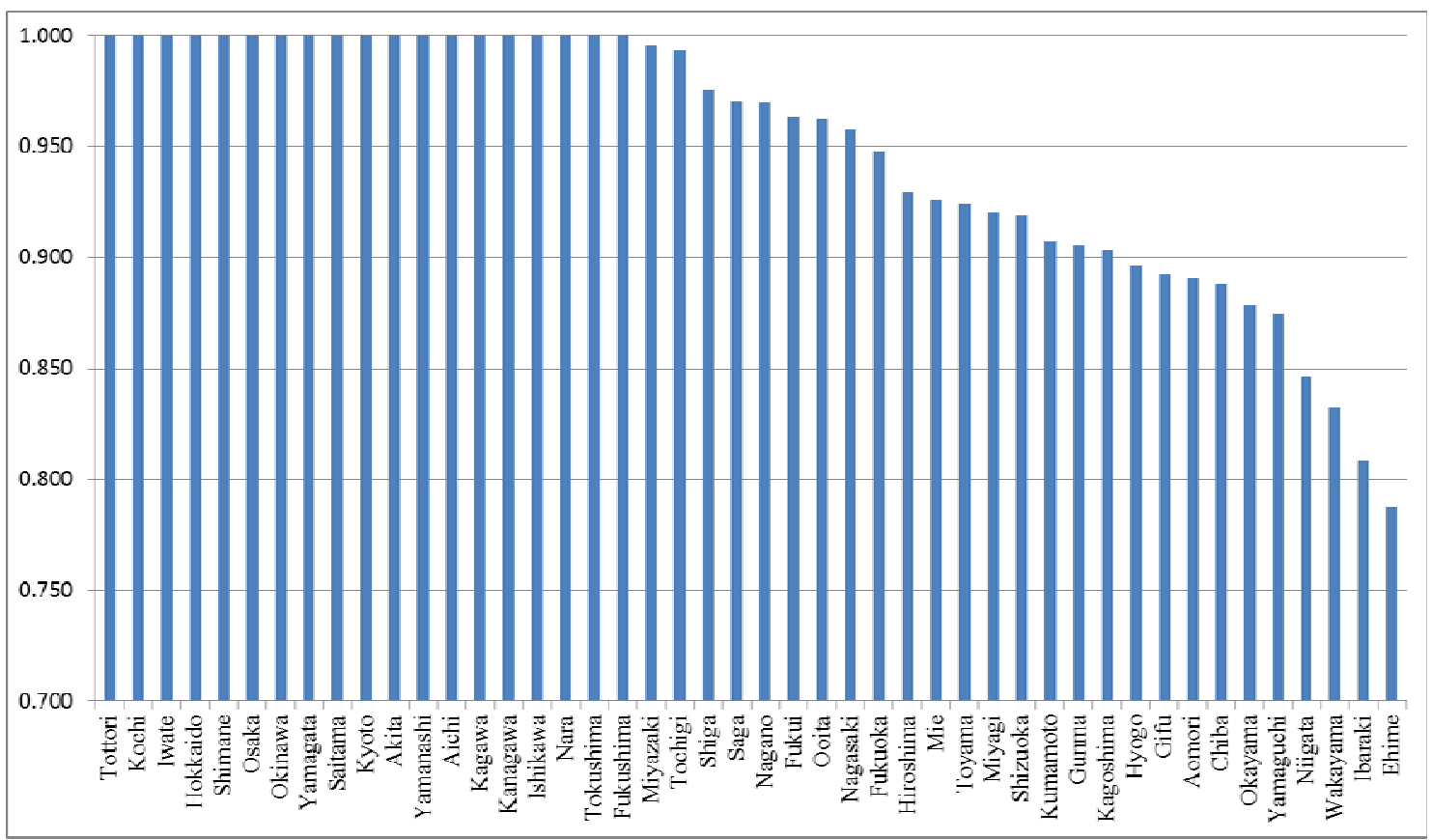

Figure 8 Efficiency score based on the CCR model

\subsection{Efficiency improvement projection based on the CCR, EDM and PB-EDM models}

The efficiency improvement projection results based on the CCR, EDM and PB-EDM models for the 27 inefficient prefectures are presented in Tables 1-A and 1-B. In the case of the PB-EDM model, we apply an OAP parameter of 0.5. In Section 5.4 we will show that the outcomes change when the decision maker changes his preference parameter OAP.

In Table 1, it appears that the empirical ratios of change in the EDM projection are smaller than those in the CCR projection, as may be expected. In Table 1, this particularly applies to Miyagi, Ibaraki, Chiba, Niigata, Gifu, Wakayama, Hiroshima, Ehime, and Kagoshima which are apparently non-slack type (i.e. $s^{-* *}$ and $s^{+* *}$ are zero) prefectures. The EDM projection involves both input reduction and output increase, and, clearly, the EDM projection does not involve a uniform ratio, because this model looks for the optimal input reduction (i.e. the shortest distance to the frontier, or Euclidean Distance Minimization). 
Table 1-A Efficiency-improvement projection results of the CCR, EDM and PB-EDM models

\begin{tabular}{|c|c|c|c|c|c|c|c|c|c|}
\hline & & & & & & \\
\hline & CCR & EDM & PB-EDM & & & CCR & EDM & PB-EDM \\
\hline DMU & Score & \multicolumn{3}{|c|}{ Score $\left(\theta^{* *}\right)$} & DMU & Score & \multicolumn{3}{|c|}{ Score $\left(\theta^{* *}\right)$} \\
\hline $1 / 0$ & ata & $\%$ & $\%$ & $\%$ & $1 / 0$ & Data & $\%$ & $\%$ & $\%$ \\
\hline Aomori & 89 & 1.000 & 1.0 & 1.000 & yama & 0.924 & 1.000 & 1.000 & 1.000 \\
\hline (I)PCS & 732022 & $0.92 \%$ & $0.00 \%$ & $0.00 \%$ & PCS & 9211105 & $-29.96 \%$ & $-28.17 \%$ & $-28.10 \%$ \\
\hline (I)PSCS & 518020 & $10.92 \%$ & $-6.68 \%$ & $-6.32 \%$ & PSCS & 15059522 & $-24.42 \%$ & $-20.93 \%$ & $-20.78 \%$ \\
\hline (I)Labour & 685401 & $10.92 \%$ & $0.00 \%$ & $0.00 \%$ & Labour & 578051 & $-7.56 \%$ & $-3.93 \%$ & $-3.78 \%$ \\
\hline $\mathrm{EC}$ & & $19.35 \%$ & $-11.33 \%$ & $-11.20 \%$ & & & $-27.21 \%$ & $-24.08 \%$ & $-23.95 \%$ \\
\hline GDP & 09 & $0.00 \%$ & $6.71 \%$ & $7.12 \%$ & SDP & 490 & $0.00 \%$ & $4.51 \%$ & $4.70 \%$ \\
\hline Sink & & $0.00 \%$ & $0.00 \%$ & $0.00 \%$ & & & $0.00 \%$ & $0.00 \%$ & $0.00 \%$ \\
\hline (O)CE & .326862 & $40.89 \%$ & $52.51 \%$ & $52.62 \%$ & כ)CE & .425568 & $0.00 \%$ & $0.00 \%$ & $0.00 \%$ \\
\hline & & 1.000 & 1.000 & 1.000 & & & 1.000 & 1.000 & 1.000 \\
\hline & 658 & $-24.28 \%$ & $0.00 \%$ & $0.00 \%$ & & 7091840 & $-10.17 \%$ & $-9.33 \%$ & $-9.32 \%$ \\
\hline SCS & & $-7.99 \%$ & $-7.62 \%$ & $-7.32 \%$ & $\mathrm{CS}$ & 1052 & $-29.40 \%$ & $-27.59 \%$ & $-27.55 \%$ \\
\hline (I)Labour & 107773 & $-7.99 \%$ & $0.00 \%$ & $0.00 \%$ & abour & & $-3.66 \%$ & $-1.86 \%$ & $-1.83 \%$ \\
\hline (I)EC & 20022 & $-20.52 \%$ & $0.00 \%$ & $0.00 \%$ & & 8713 & $-16.47 \%$ & $-14.63 \%$ & $-14.60 \%$ \\
\hline GDP & 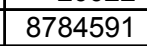 & $0.00 \%$ & $4.30 \%$ & $4.49 \%$ & DP & 3281 & $0.00 \%$ & $2.44 \%$ & $2.49 \%$ \\
\hline ink & & $0.00 \%$ & $0.00 \%$ & $0.00 \%$ & & & $0.00 \%$ & $0.00 \%$ & $0.00 \%$ \\
\hline (O)CE & 84 & $0.00 \%$ & $0.00 \%$ & $0.00 \%$ & & 0.61 & $0.00 \%$ & $0.00 \%$ & $0.00 \%$ \\
\hline & & 1.000 & 1.000 & 1.000 & gano & 0.970 & 1.000 & 1.000 & 1.000 \\
\hline $\mathrm{CS}$ & 0 & $-25.33 \%$ & $0.00 \%$ & $0.00 \%$ & & 03 & $-2.96 \%$ & $0.00 \%$ & $0.00 \%$ \\
\hline SCS & 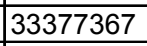 & \begin{tabular}{|l|}
$-19.20 \%$ \\
\end{tabular} & $0.00 \%$ & $0.00 \%$ & & 45 & $-2.96 \%$ & $-3.01 \%$ & $-2.97 \%$ \\
\hline abour & & $-19.20 \%$ & $-14.53 \%$ & $-13.14 \%$ & bour & & $-2.96 \%$ & $0.00 \%$ & $0.00 \%$ \\
\hline (I)EC & & \begin{tabular}{|l|}
$-21.59 \%$ \\
\end{tabular} & $0.00 \%$ & $0.00 \%$ & & & $-3.53 \%$ & $-1.64 \%$ & $-1.62 \%$ \\
\hline (O)GDP & 07 & $0.00 \%$ & $10.84 \%$ & 12120 & GDP & 94 & $0.00 \%$ & $1.73 \%$ & $1.76 \%$ \\
\hline ink & & $0.00 \%$ & $0.00 \%$ & & & & $0.00 \%$ & $.00 \%$ & $0.00 \%$ \\
\hline (O)CE & 0.11 & $0.00 \%$ & $0.00 \%$ & $0.00 \%$ & & 0.30 & $4.78 \%$ & $2.49 \%$ & $2.43 \%$ \\
\hline Tochigi & & 1.000 & 1.000 & 1.000 & & & 1.000 & 1.000 & 1.000 \\
\hline (I)PCS & 04 & $0.72 \%$ & $-0.36 \%$ & $036 \%$ & & 41 & $0.76 \%$ & $-10.78 \%$ & $-10.20 \%$ \\
\hline (I)PSCS & 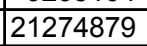 & $.69 \%$ & $-3.20 \%$ & $-3.19 \%$ & CS & 182 & $0.76 \%$ & $0.00 \%$ & $0.00 \%$ \\
\hline (I)Labour & & $1 \%$ & & & bour & 54 & $76 \%$ & $0 \%$ & $0.00 \%$ \\
\hline (I)EC & & $-12.90 \%$ & $12.46 \%$ & $2.46 \%$ & & & $-18.75 \%$ & $.00 \%$ & $0.00 \%$ \\
\hline (O)GDP & 18 & $0.00 \%$ & $0.51 \%$ & $0.51 \%$ & & 10 & $0.00 \%$ & $79 \%$ & $8.26 \%$ \\
\hline & & $00 \%$ & $0.00 \%$ & & & & $0.00 \%$ & $0 \%$ & $0.00 \%$ \\
\hline $\mathrm{CE}$ & & & $0.00 \%$ & & & 5 & $24.20 \%$ & & $0.00 \%$ \\
\hline ma & & 1.000 & 1.000 & 1.000 & loka & & 1.000 & 1.000 & 1.000 \\
\hline (I)PCS & & $.43 \%$ & $-4.95 \%$ & $4.71 \%$ & & 02 & $-8.1 \%$ & $-5.6 \%$ & $-5.4 \%$ \\
\hline (I)PSCS & & $.64 \%$ & & & & & $-8.12 \%$ & $0.00 \%$ & $0.00 \%$ \\
\hline (I)Labour & & & & & 0 & 199 & $-8.12 \%$ & $0.04 \%$ & $.00 \%$ \\
\hline (I)EC & & $3 \%$ & $\%$ & $\%$ & & 74 & $-22.65 \%$ & \begin{tabular}{|l|}
$-11.67 \%$ \\
\end{tabular} & $-11.87 \%$ \\
\hline (O)GDP & 472226 & $0.00 \%$ & $7.68 \%$ & $8.08 \%$ & $\mathrm{DP}$ & 02 & $0.00 \%$ & $4.99 \%$ & $5.21 \%$ \\
\hline (O)Sink & & $00 \%$ & & & & & $0.00 \%$ & $0.00 \%$ & $0.00 \%$ \\
\hline & & $5 \%$ & & & & .13 & $46.69 \%$ & $32.87 \%$ & $33.69 \%$ \\
\hline$a$ & & .000 & 1.000 & 1 & & & 1.000 & 1.000 & 1.000 \\
\hline (I)PCS & 95 & $.19 \%$ & $0.00 \%$ & 07 & & 145 & $14.47 \%$ & $-12.15 \%$ & $-12.06 \%$ \\
\hline (I)PSCS & 4601 & $-11.19 \%$ & $-9.53 \%$ & $-8.99 \%$ & SCS & 282 & $-15.53 \%$ & $-11.95 \%$ & $-11.81 \%$ \\
\hline (I)Labour & & & & & & & $-7.36 \%$ & $-3.82 \%$ & $-3.68 \%$ \\
\hline & & & & & & & $30.16 \%$ & \begin{tabular}{|l}
$-27.27 \%$ \\
\end{tabular} & $-27.16 \%$ \\
\hline (O)GDP & 2055 & $0.00 \%$ & $7 \%$ & $4 \%$ & & 522 & $0.00 \%$ & $4.16 \%$ & $4.32 \%$ \\
\hline (O)Sink & & $00 \%$ & $0.00 \%$ & 0 & & & $0.00 \%$ & $0.00 \%$ & $0.00 \%$ \\
\hline D)CE & .064 & $45.40 \%$ & & 00 & & 87 & $0.00 \%$ & $0.00 \%$ & $0.00 \%$ \\
\hline ata & & & & & & & 1.000 & 1.000 & 1.000 \\
\hline (I)PCS & 853071 & \begin{tabular}{|l|}
$-42.83 \%$ \\
\end{tabular} & $0.00 \%$ & $0.00 \%$ & & 789565 & $-5.30 \%$ & $-4.46 \%$ & $-4.45 \%$ \\
\hline (I)PSCS & 25666267 & $-21.37 \%$ & $0.00 \%$ & $0.00 \%$ & SCS & 15773767 & $-6.91 \%$ & $-5.60 \%$ & $-5.58 \%$ \\
\hline (I)Labour & 1225575 & $-15.39 \%$ & $0.00 \%$ & $0.00^{\circ}$ & shour & 680478 & $-2.46 \%$ & $-1.25 \%$ & $-1.23 \%$ \\
\hline & & $-15.39 \%$ & $14.48 \%$ & $-13.37 \%$ & & & $-21.03 \%$ & $-19.98 \%$ & $-19.96 \%$ \\
\hline (O)GDP & 9221176 & $0.00 \%$ & $9.12 \%$ & $9.95 \%$ & (O)GDP & 6284265 & $0.00 \%$ & $1.39 \%$ & $1.40 \%$ \\
\hline (O)Sink & 1139378 & $.00 \%$ & & & & & $0.00 \%$ & $0.00 \%$ & $0.00 \%$ \\
\hline O)CE & 0.215737 & $17.52 \%$ & $0.00 \%$ & $0.00 \%$ & (O)CE & 0.436405 & $0.00 \%$ & $0.00 \%$ & $0.00 \%$ \\
\hline
\end{tabular}


Table 1-B Efficiency-improvement projection results of the CCR, EDM and PB-EDM models

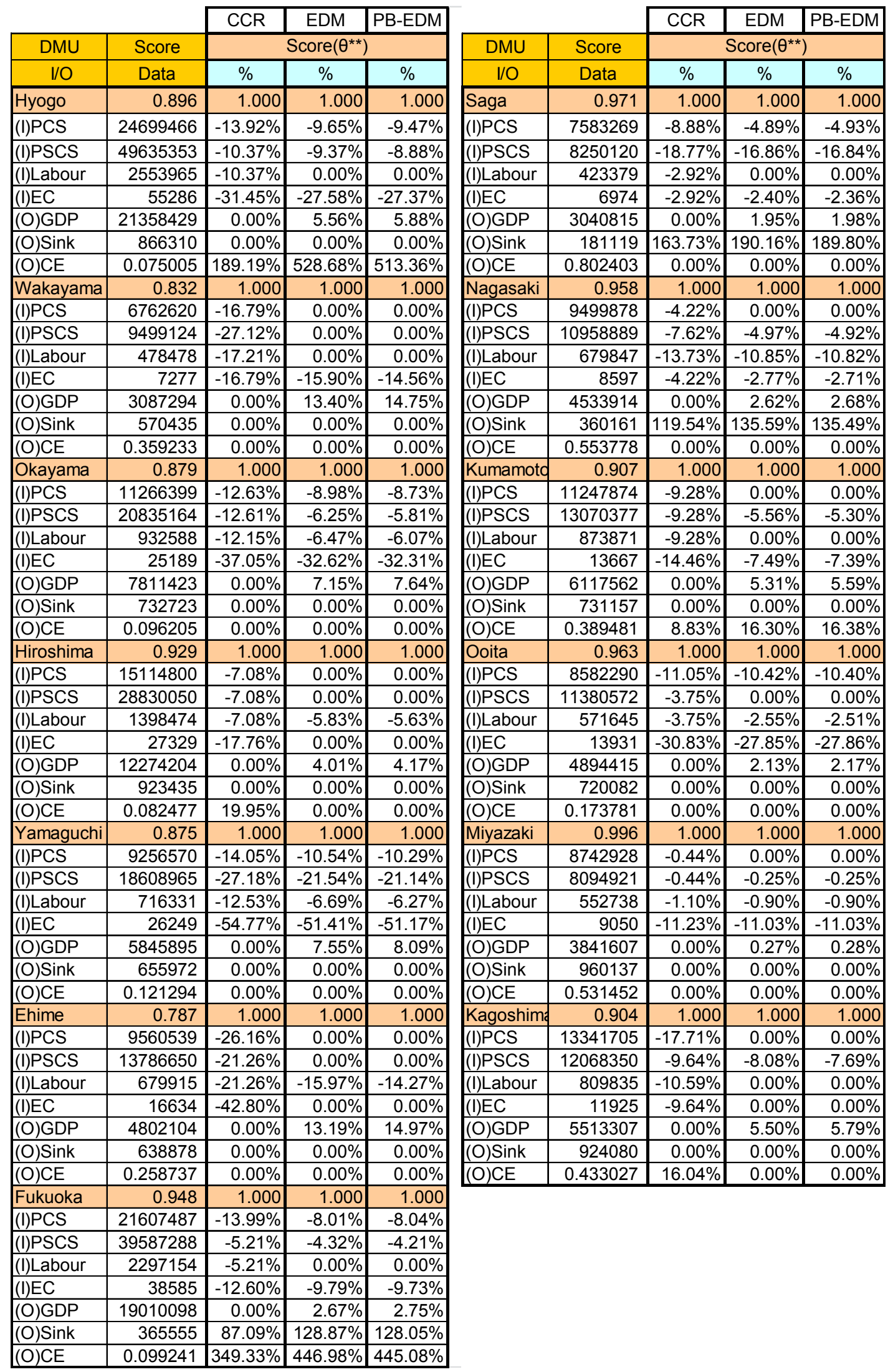


For instance, the CCR projection shows that Wakayama should reduce its Public Capital Stock (PCS) and Electricity Consumption (EC) by 16.79 percent, Private Sector Capital Stock (PSCS) by 27.12percent, Labour by 17.21percent, in order to become efficient.

On the other hand, the EDM results show that a reduction in Electricity Consumption (EC) of 15.90 percent, and an increase in GDP of 13.40 percent are required for Wakayama to become efficient. Furthermore, the PB-EDM results show that a reduction in the Electricity Consumption (EC) of $14.56 \%$, and an increase in the GDP of $14.75 \%$ are required to become efficient. Apart from the practicality of such a solution, the models show clearly that a different - and perhaps more efficient solution is available than the standard CCR projection to reach the efficiency frontier.

\subsection{Efficiency improvement projection of the PB-EDM model}

In this subsection, we use Wakayama as an example of an inefficient reference prefecture, and present an efficiency improvement projection result based on the PB-EDM model. We assume that the OAP uses steps from 0.0 to 1.0 at intervals of 0.1 . Next, the input reduction values and the output increase values based on the PB-EDM model are calculated in Figure 9.

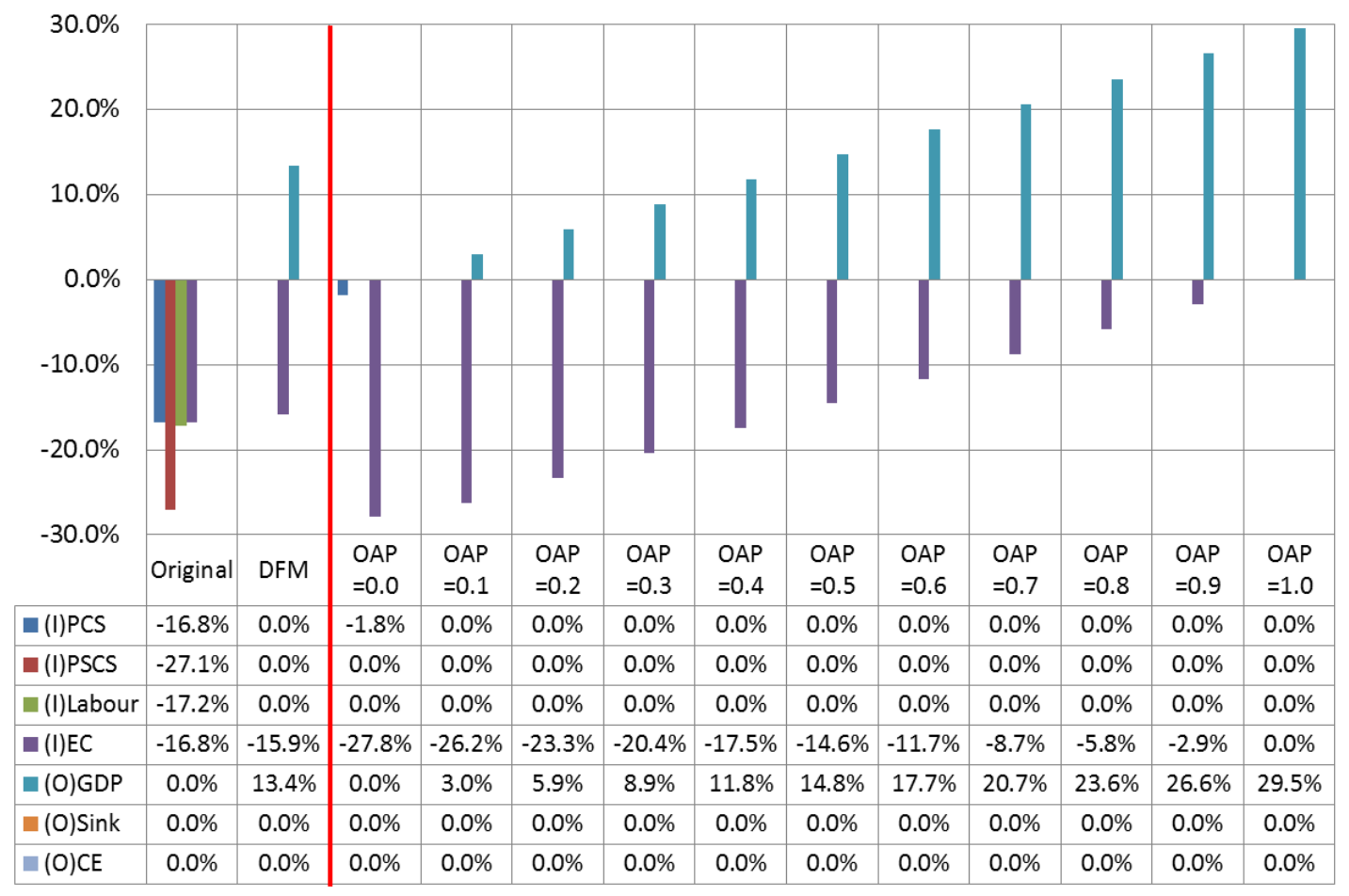

Figure 9 Efficiency improvement projection results based on the PB-EDM model (for Wakayama)

These results show that, if the prefecture implements an efficiency improvement plan with an OAP amounting to 0.3 (i.e. 30 percent of the total efficiency gap is allocated for output, and 70 percent of the 
total efficiency gap is allocated for input), a reduction in EC of 20.4 percent, and an increase in GDP of 8.9 percent are required, then the efficiency score improved to reach 1.000. Furthermore, the results of a plan with an OAP of 0.0 (i.e. 100 percent of the total efficiency gap is allocated for input), a reduction in EC of 27.8 percent and in the PCS of 1.8 percent are required, to improve the efficiency score towards 1.000 .

\section{Conclusion}

In this paper we have presented a new methodology, the PB-EDM model. This model is characterized by two integrated features: (i) the use of a general Euclidean Distance Method (EDM) to achieve the most appropriate movement towards the efficiency frontier surface, (ii) the incorporation of preference-based (PB) adjustments in efficiency strategies regarding the input reduction allocation - or the output increase allocation - of DMUs in order to balance rigorous efficiency decisions with political priorities.

The results of this methodology may offer a meaningful contribution for the decision making and planning for the improvement of Energy-Environment-Economic efficiency for each prefecture in Japan. And this new model may thus become a policy instrument that may have great added value for decision making and planning. For example, an agreement on an Energy-Environment-Economic balance policy where all inefficient prefectures have to improve their efficiency (to reach the score 1.000), but where the balance of input-output improvement can be freely set based on the preferences of each prefecture. This framework might be the basis of a new concept like the "Kyoto Protocol" for each prefecture in Japan.

\section{References}

Agency for Natural Resources and Energy, Ministry of the Economy, Trade and Industry in Japan, "Statistical report on energy consumption for each prefecture", and "Statistics report on comprehensive strategy for energy consumption and environment", 2008.

Cabinet Office, Government of Japan, "Economic and Fiscal model for Prefectures", 2008

Charnes, A., Cooper, W.W. and Rhodes, E., "Measuring the Efficiency of Decision Making Units", European Journal of Operational Research, 2, 1978, pp. 429-444.

Golany, B., "An Interactive MOLP Procedure for the Extension of DEA to Effectiveness Analysis", Journal of the Operational Research Society, 39, 1988, pp. 725-734.

Halme, M., Joro, T., Korhonen, P., Salo, S. and Wallenius, J., "A value efficiency approach to incorporating preference information in Data Envelopment Analysis", Management Science, 45, (1), 1999, pp. 103-115.

Joro, T., Korhonen, P. and Wallenius, J., "Structural Comparison of Data Envelopment Analysis and Multiple Objective Linear Programming", Management Science, 44, (7), 1998, pp. 962-970.

Korhonen, P. and Siljamäki. A., "On the Use of Value Efficiency Analysis and Some Further 
Developments", Journal of Productivity Analysis, 17, (1-2), 2002, pp. 49-64.

Korhonen. P., Stenfors, S. and Syrjänen. M., "Multiple objective approach as an alternative to radial projection in DEA", Journal of Productivity Analysis, 20, (20), 2003, pp. 305-321.

Lins, M. P. E., Angulo-Meza, L. and Moreira da Silva, A.C., "A multi-objective approach to determine alternative targets in data envelopment analysis", Journal of Operational Research, 55, 2004, pp. 1090-1101.

Seiford, L., A Cyber-Bibliography for Data Envelopment Analysis (1978-2005), August, 2005

Statistics Bureau, Ministry of Internal Affairs and Communication, "Census Return 2005”, 2005

Sugihara, H. et al. "Carbon pool of Japanese islands", Studies in Regional Policy (Development Bank of Japan), Vol.11, 2004, pp.1-49.

Suzuki, S., Nijkamp, P., Rietveld, P. and Pels, E., "A Distance Friction Minimization Approach in Data Envelopment Analysis: A Comparative Study on Airport Efficiency", European Journal of Operational Research, 207, 2010, pp.1104-1115.

Thanassoulis, E., and Dyson, R.G., "Estimating Preferred Target Input-Output Levels Using Data Envelopment Analysis," European Journal of Operational Research, 56, 1992, pp. 80-97.

Washio,S., Yamada, S., Tanaka, T. and Tanino, T., "Improvements by analyzing the efficient frontier in DEA,” European Journal of Operational Research, 217, 2012, pp.173-184.

Yang, X., Morita, H., "Efficiency improvement from multiple perspectives: An application to Japanese banking industry," Omega, 41, Issue3, 2013 (forthcoming). 


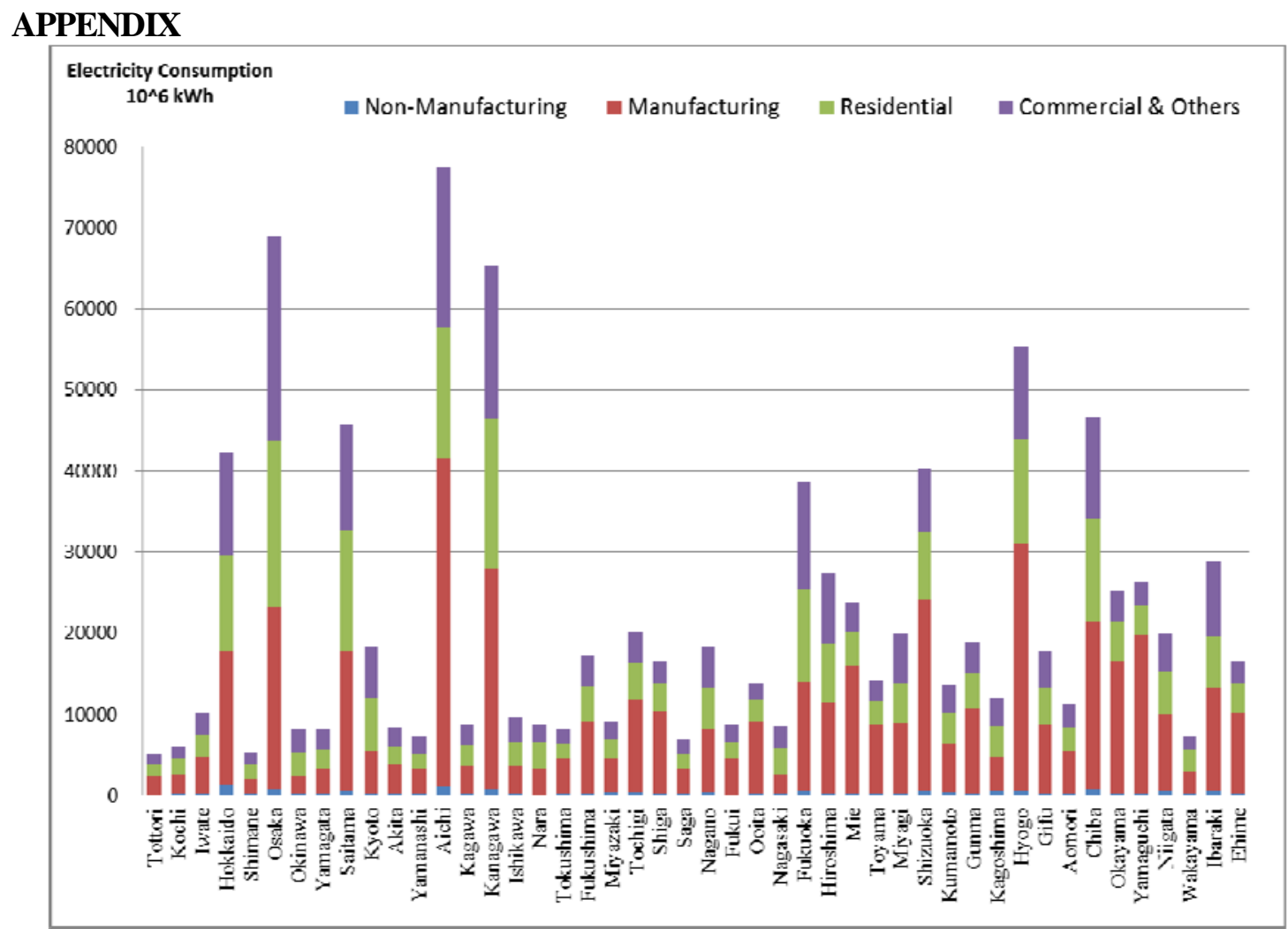

Figure A1 Electricity consumption of sectors (large classification) in each prefecture (score-ordered) 


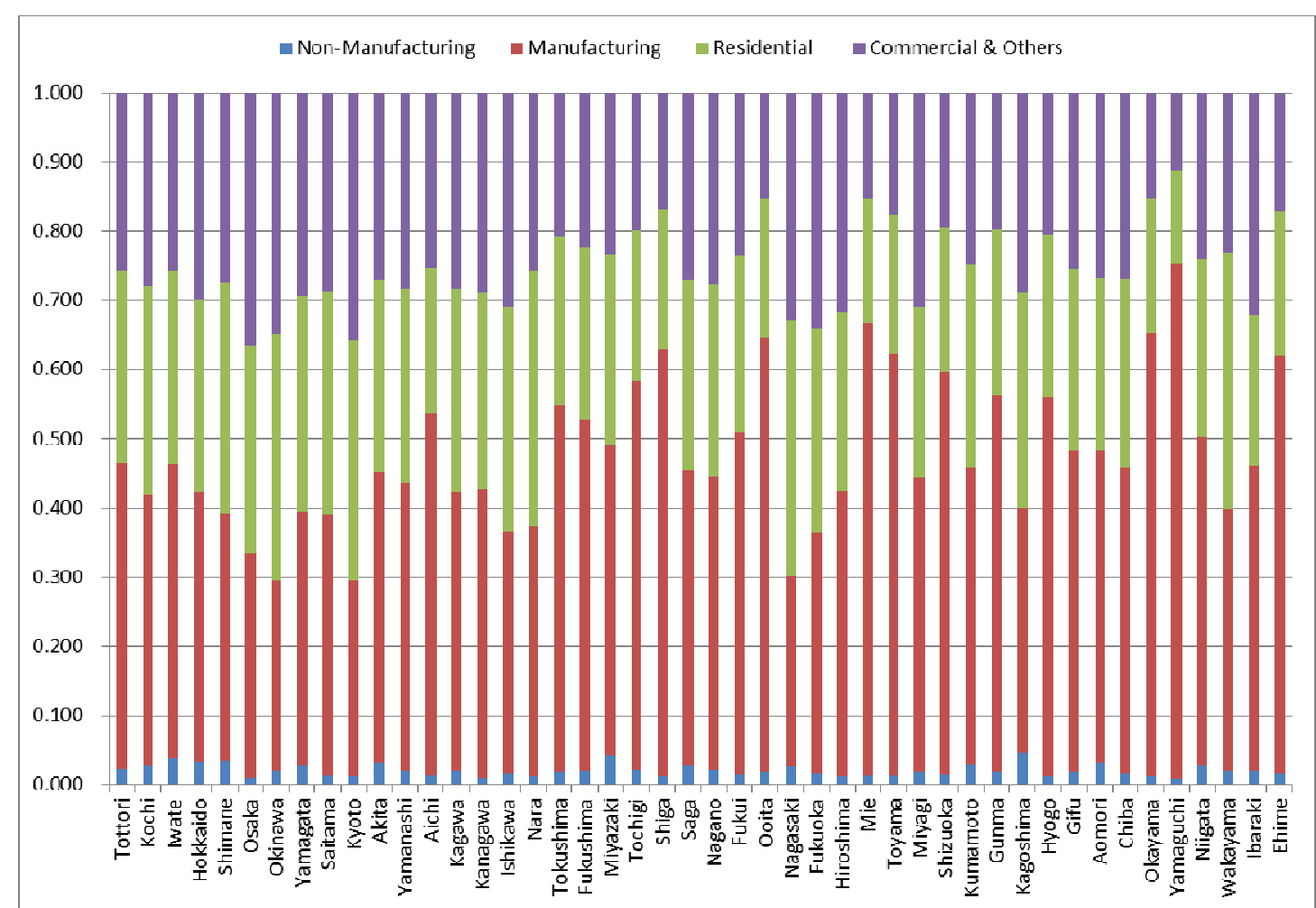

Figure A2 Electricity consumption share of sectors (large classification) in each prefecture (score-ordered)

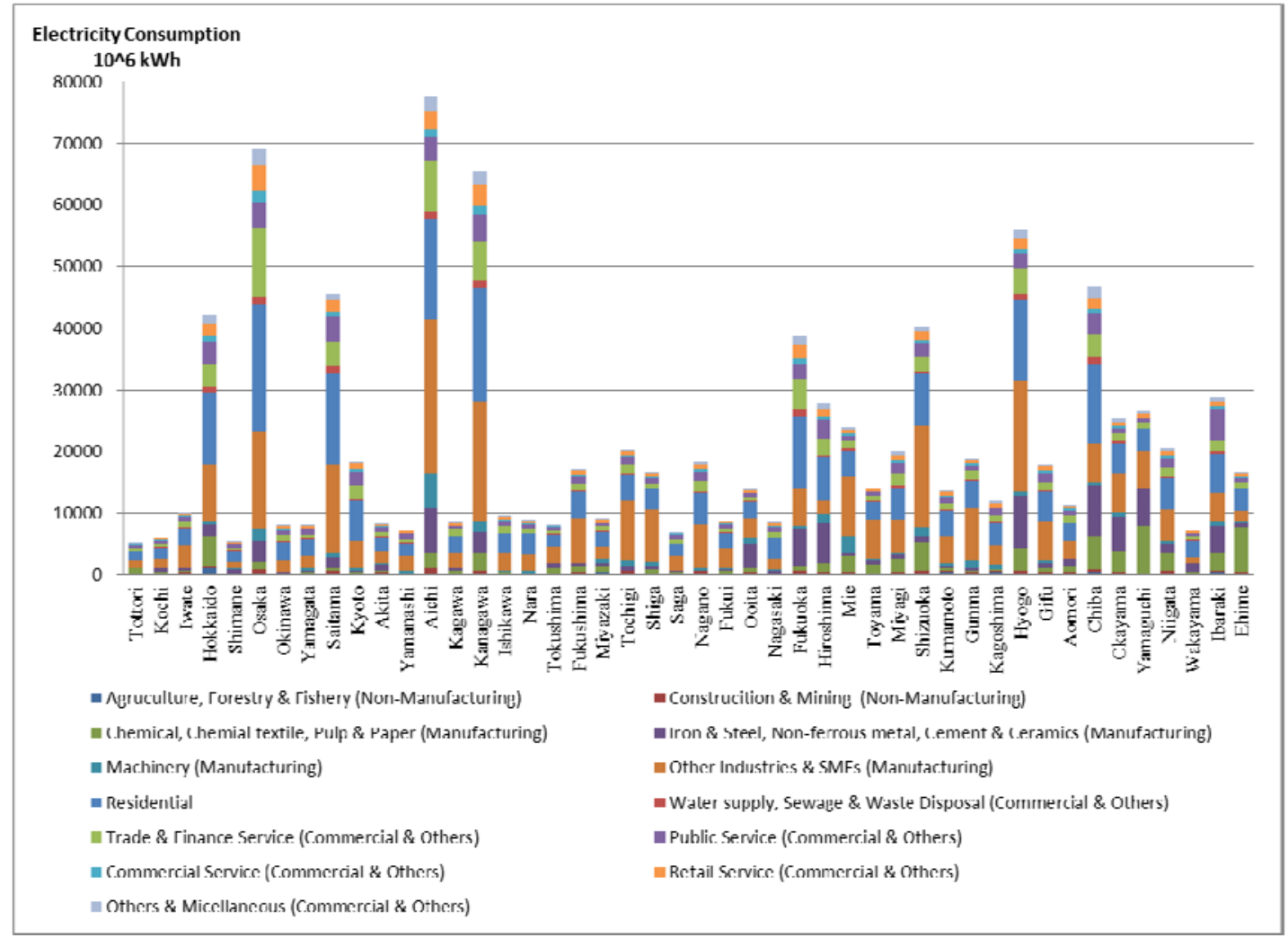

Figure A3 Electricity consumption of sectors (small classification) in each prefecture (score-ordered) 


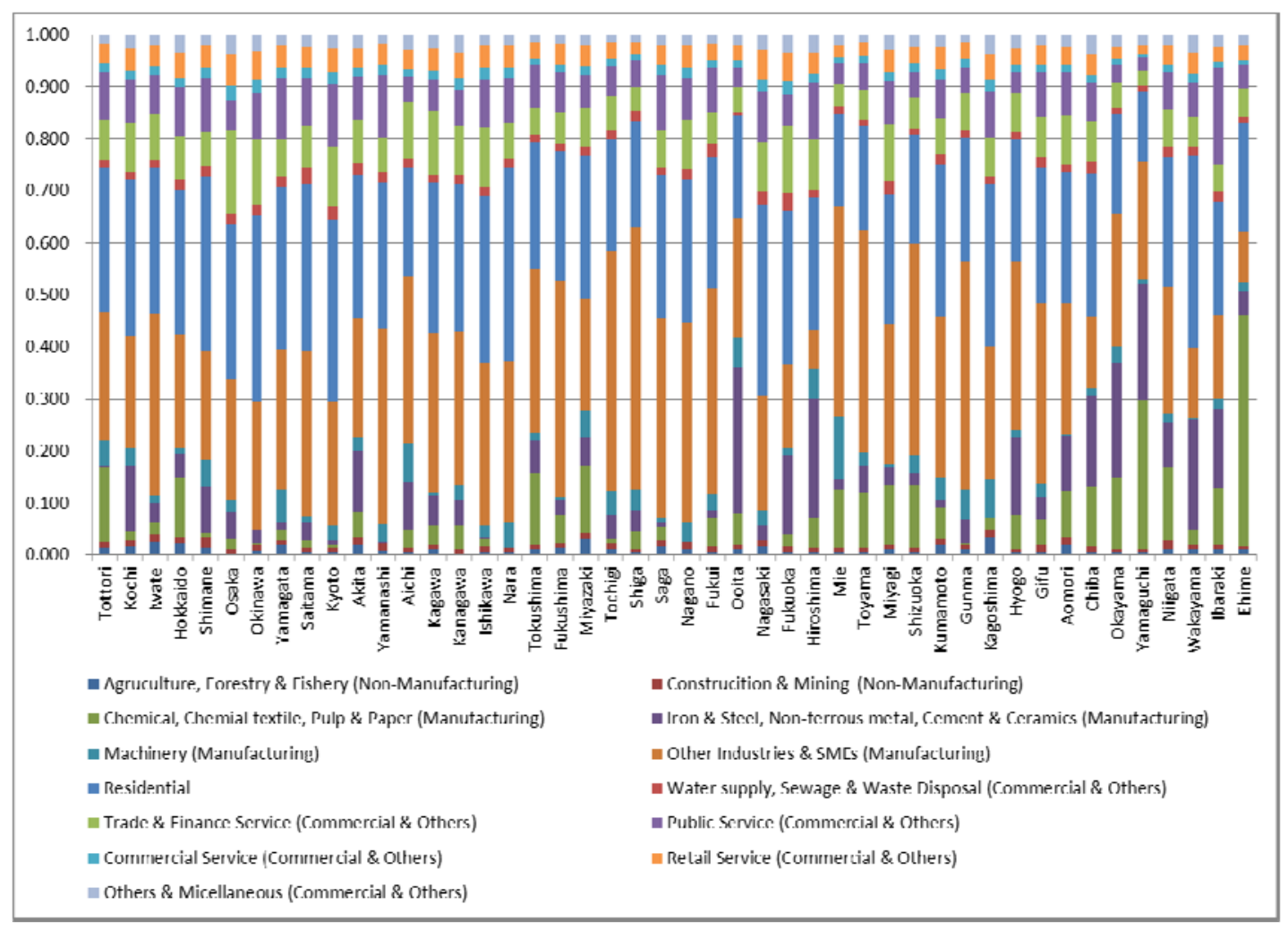

Figure A4 Electricity consumption share of sectors (small classification) in each prefecture (score -ordered) 